\title{
Erratum to: Is the use of thin, highly cross-linked polyethylene liners safe in total hip arthroplasty?
}

\author{
Julio J. Jauregui ${ }^{1} \cdot$ Qais Naziri $^{2} \cdot$ Todd P. Pierce $^{1} \cdot$ Randa K. Elmallah $^{1}$. \\ Jeffrey J. Cherian ${ }^{1} \cdot$ Ronald E. Delanois ${ }^{1} \cdot$ Michael A. Mont ${ }^{1}$
}

Published online: 9 June 2016

(C) SICOT aisbl 2016

Erratum to: International Orthopaedics (SICOT) (2016) 40:681-686

DOI 10.1007/s00264-015-2841-4

No Disclosure of potential conflicts of interest was published in the article.

\section{Please see below the missing Disclosure text:}

Dr. Mont reports grants and personal fees from DJ Orthopaedics, grants and personal fees from Johnson and Johnson, personal fees from Medical Compression Systems, personal fees from Merz, other from Microport, grants from National Institutes of Health, grants from Ongoing Care Solutions, grants and personal fees from Orthosensor, personal fees from Pacira, personal fees from Sage Products, Inc, grants, personal fees and other from Stryker, grants and personal fees from TissueGene, personal fees from US Medical Innovations, other from AAOS, other from American Journal of Orthopedics, other from Journal of Arthroplasty, other from Journal of Knee Surgery, other from Orthopaedics, other from Surgical Technology International, outside the submitted work.

JJC is a paid consultant for DJ Orthopaedics and Pacira Pharmaceuticals, Inc.

RED is a paid consultant and paid presenter/speaker for Cayenne Medical, and is a board/committee member for the Maryland Orthopaedic Association.

QN, TPP, and RKE have nothing to disclose.

The online version of the original article can be found at http://dx.doi.org/ 10.1007/s00264-015-2841-4.

Michael A. Mont

mmont@lifebridgehealth.org; rhondamont@aol.com

1 Center for Joint Preservation and Replacement, Rubin Institute for Advanced Orthopedics, Sinai Hospital of Baltimore, 2401 West Belvedere Avenue, Baltimore, MD 21215, USA

2 Department of Orthopaedic Surgery, SUNY Downstate Medical Center, Brooklyn, NY, USA 